\title{
Motivation Through Incentives: From FCHVs' Perspectives
}

\author{
Rajan Sharma \\ rajansharma@iom.edu.np
}

\begin{abstract}
"In every community, there is work to be done. In every nation, there are wounds to heal. In every heart, there is the power to do it."
\end{abstract}

\section{-Marianne Williamson}

Community Health workers (CHWs) are referred to as the backbone of a health system. A few of them receive some sort of incentives while the other end receives no particular enticements. Just to mention, they work in a number of countries under vast array of tag names (Such as: Activista Anganwadi-Mozambique, Animatrice-Haiti, Barangay health worker-Philippines, Basic health worker- India, Brigadista-Nicaragua, Colaborador voluntario-Guatemala, Community health agent-Ethiopia, Community health promoter-Zambia, Community resource person-Uganda, Kader-Indonesia, Monitora/ Promotora - Honduras, Rural health motivator-Swaziland, Village health helper-Kenya among others). Whatever their names may be, a million dollar question arising in the dullest of all brains is: What keeps them going?

In our case, Female community health volunteers (FCHVs) are often referred to as the force behind the occasional achievements in health segment particularly at the grassroot level. Be it Millennium Development Goal (MDG)-4 of reducing the child mortality by two-thirds or MDG-5 of reducing Maternal Mortality (MMR) by three-quarters, the role of FCHVs will be crucial if not decisive. Like any other CHWs, FCHVs do not exist in a vacuum. They are part of and are influenced by the larger cultural and political environment in which they work. ${ }^{[1]}$ They need some motivational tools, of course, to move on and to continue serving the community people.

Incentives can be the answers but they are surrounded by pros and cons. It is high time that we dissected them.

\section{Forms of incentives:}

Monetary incentives can play a pivotal role in the functionality of the volunteers. Most of the FCHVs are economically fragile who have to support their families and sustain themselves as well. So, money can operate in a twoway process: motivating the volunteers to get engaged as well as supporting them economically thus contributing to better retention.

There's no lack of incentives that offer money to these volunteers. Travel and daily allowances aren't new in Nepal during trainings, reviews, refreshers and during health campaigns. The government on the other hand has set up FCHV funds in every VDCs which is a solid system for the volunteers to be benefitted financially.

On the other hand, there are many programs in Nepal which involve direct allowances in the form of money. One of such examples is: Community Based Newborn Care Program (CBNCP). In CBNCP, if a FCHV fills out the form two which includes essential newborn care services provided in the first 28 days after birth including follow up then she is liable to get certain amount of cash based on performance, quantified in terms of percentage. That is, the highest performing FCHVs (70\% or over) gets NRs. $400,60 \%-70 \%$ NRs. 300, 50\%-60\%-Rs. 200 and there's no money for performance less than $50 \%$. Similarly, in some districts like Kavre, a number of VDCs provide money (mostly NRs. 100) for attending monthly meetings.

Monetary incentives are, however, accompanied by a host of problems because the money may not be enough, may not be paid regularly, or may stop altogether. ${ }^{[1]}$ In Nepal too, such schemes have brought a wide spectrum of problems. Many older FCHVs who are physically and physiologically feeble do not opt to give up working because of increasing monetary supporting programs like CBNCP. These impacts are vaguely expressed. An exploration into the detailed impact of such schemes is sure to convey out both positive and negative consequences of such monetary incentives.

\section{Non-monetary incentives:}

'Money is not everything' principle not only applies in literal philosophy but also proves critical to the success of FCHVs program as well. Monetary incentives do motivate these workers but non-monetary enticements are equally important too. An example from Zambia can be a good example how volunteers can be motivated without cash payments where Ministry of health sometimes sends the letters of appreciation to such workers and their families to express appreciation although it isn't a norm. ${ }^{[2]}$ They may also include supportive supervision and appropriate training. Similarly, provision of identification card, job aids, timely reimbursement of supplies and refresher/review trainings also induce the volunteers to work for the community. Sometimes, an alternative to monetary motivation can be choosing an alternative path although they may not be feasible or possible in each and every case. 
Prevention is better than cure, of course but prevention is extremely hard to sell in all public health programs. When curative care is offered, it is generally more welcomed and appreciated by the residents. ${ }^{[3][4][5][6]}$ In Nepal, when FCHVs were allowed to administer cotrimoxazole $\mathrm{p}$ tablets against fast breathing as a major sign of ARI, their ability to treatment increased their motivation. ${ }^{[3]}$ Thus, including a curative part can trigger positivism in the volunteers which wouldn't have been possible through cash incentive alone. Nonmonetary motivation, however, can only act as a complementary method to the pecuniary one as they barely fulfill personal needs of the volunteers.

\section{Alternatives to monetary incentives:}

In-kind payment is a system involving the paying the volunteers in kind rather in cash. It is advantageous because their exact values are difficult to monetize. In kind support can involve food rations, housing, and child care services. One such effort in Peru where beneficiary families in Peru work in turns on the farms of the volunteers in recognition of their valuable contribution is exemplary. ${ }^{[7]}$ It can be a great example for our country too but the role played by FCHVs has to be realized by community people at first. Similarly, NGOs/INGOs can contribute in-kind payments include bags to carry supplies, agricultural tools, raincoats, backpacks, supplies for home improvement, educational materials, herbal plants, and fruit trees

Preferential treatment is another way to demonstrate appreciation for their works through access to credit programs, literacy classes, or first-in-line treatment at health posts or hospitals (as in Ghana). ${ }^{[8]}$

Multiple incentives are the process of combining incentives (both extrinsic and intrinsic) simultaneously. It can have positive effect on continuing sense of satisfaction and fulfillment in the volunteers. Examples of programs using multiple incentives include: Atención Integral a la Niñez, Hondurus, Jereo Salama Isika, Madagascar, Afghanistan Health Sector Support Project (AHSSP) among others.

However, experience has shown that any kind of financial support or subsidy, despite its positive short-term impact, is problematic for long-term sustainability. ${ }^{[9]}$

Conclusion: There is no single-shot solution to keep motivating volunteers to work in and for the community. Cash and non-cash incentives both have pros and cons and the balanced and simultaneous use of different incentives in the form of multiple incentives can be a better idea. Not only incentives of any form will keep these volunteers get going but also supporting them to have better relations with community such as involving simple yet crucial curative components along with preventative measures will be worthy of being taken into consideration for better retaining as well as motivation.

\section{References:}

[1] Karabi Bhattacharyya, Peter Winch, Karen LeBan, and Marie Tien. Community Health Worker Incentives and Disincentives: How They Affect Motivation, Retention, and Sustainability. Published by the Basic Support for Institutionalizing Child Survival Project (BASICS II) for the United States Agency for International Development. Arlington, Virginia, October 2001.

[2] Steel, A. BASICS Project. Semistructured interview, 2001.

[3] Curtale, F, et al. Improving Skills and Utilization of Community Health Volunteers in Nepal. Social Science \& Medicine 40(8):1117-25, 1995.

[4] Frankel, S, and MA Doggett. The Community Health Worker: Effective Programmes for Developing Countries. New York: Oxford University Press, 1992.

[5] Heggenhougan, K. Community Health Workers: The Tanzanian Experience. New York: Oxford University Press, 1987.

[6] Walt, G. Community Health Workers: Policy and Practice in National Programs. EPC Publication No. 16. London: The Evaluation and Planning Centre, London School of Hygiene \& Tropical Medicine, 1988.

[7] Buenavente, L. Project HOPE. Personal communication, March 3, 2000.

[8] Leonard, SG, ed. Community IMCI Workshop, March 29 and 30, 2000. Consultancy to the Ministry of Health, Ghana. Arlington, Virginia: BASICS II Project, 2000.

[9] McHenry, M. Adventist Development and Relief Agency. Personal communication, March 4, 2000. 